Marquette University

e-Publications@Marquette

$8-2010$

\title{
Normal and Abnormal Personality Traits are Associated with Marital Satisfaction for both Men and Women: An Actor-Partner Interdependence Model Analysis
}

\author{
Catherine B. Stroud \\ The Family Institute at Northwestern University \\ C. Emily Durbin \\ Seema D. Saigal \\ Northwestern University \\ Lynne M. Knobloch-Fedders \\ Marquette University, lynne.knobloch-fedders@marquette.edu
}

Follow this and additional works at: https://epublications.marquette.edu/psych_fac

Part of the Psychology Commons

\section{Recommended Citation}

Stroud, Catherine B.; Durbin, C. Emily; Saigal, Seema D.; and Knobloch-Fedders, Lynne M., "Normal and Abnormal Personality Traits are Associated with Marital Satisfaction for both Men and Women: An Actor-Partner Interdependence Model Analysis" (2010). Psychology Faculty Research and Publications. 366.

https://epublications.marquette.edu/psych_fac/366 
Marquette University

\section{e-Publications@Marquette}

\section{Psychology Faculty Research and Publications/College of Arts and Sciences}

This paper is NOT THE PUBLISHED VERSION; but the author's final, peer-reviewed manuscript. The published version may be accessed by following the link in the citation below.

Journal of Research in Personality, Vol. 44, (2010): 466-477. DOI. This article is (C) Elsevier and permission has been granted for this version to appear in e-Publications@Marquette. Elsevier does not grant permission for this article to be further copied/distributed or hosted elsewhere without the express permission from Elsevier.

\section{Contents}

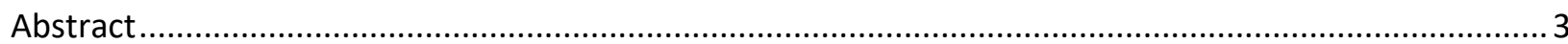

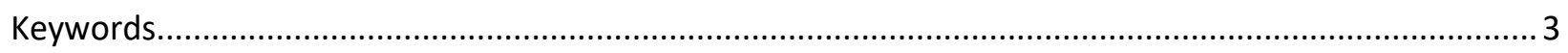

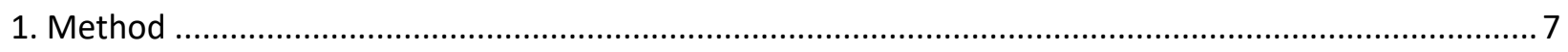

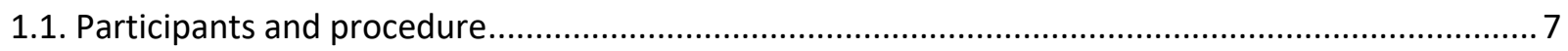

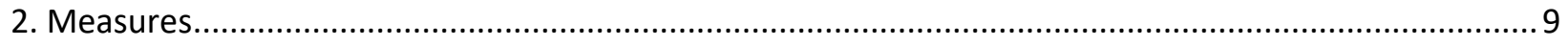

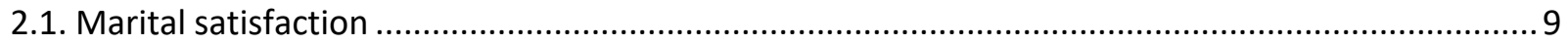

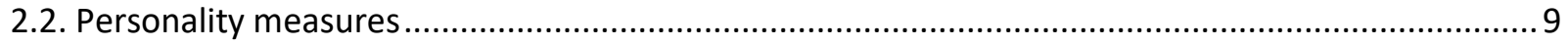

2.2.1. Multidimensional Personality Questionnaire .................................................................. 9

2.2.2. Schedule for Nonadaptive and Adaptive Personality Self-Description Rating Form ................ 10

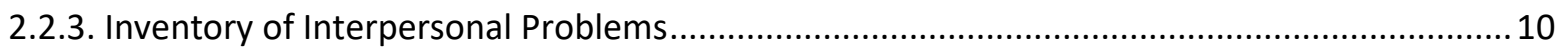

2.2.4. International Personality Disorders Examination Screener................................................ 10

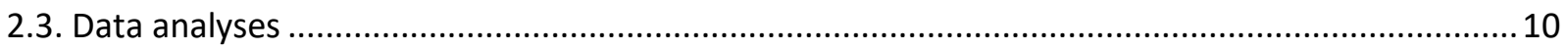

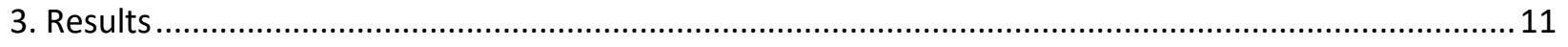

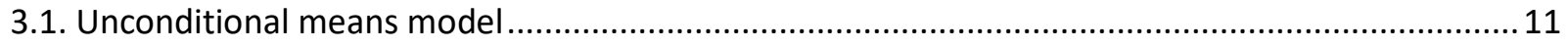

3.2. Effects of negative emotionality on marital dissatisfaction ..................................................... 12

3.3. Effects of positive emotionality on marital dissatisfaction ....................................................... 15

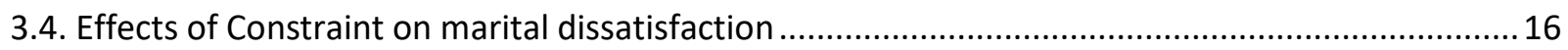


3.5. Unique effects of Negative Emotionality, Positive Emotionality, and Constraint

3.6. Effects of Openness to Experience on marital dissatisfaction .....................................................17

3.7. Effects of personality traits related to interpersonal functioning on marital dissatisfaction..........19

3.8. Effects of total personality disorder characteristics on marital dissatisfaction..............................19

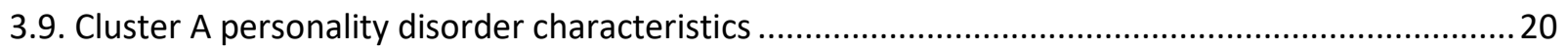

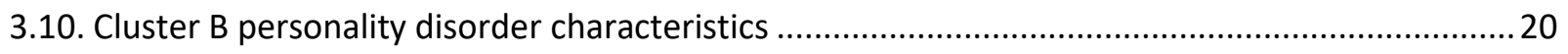

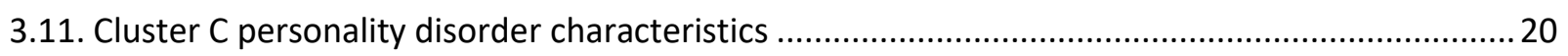

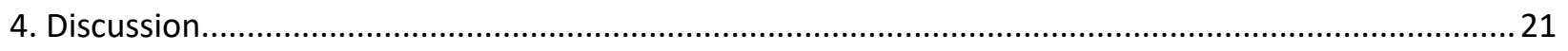

4.1. Links between Negative Emotionality and marital dissatisfaction .............................................. 21

4.2. Links between Positive Emotionality and marital dissatisfaction .............................................. 21

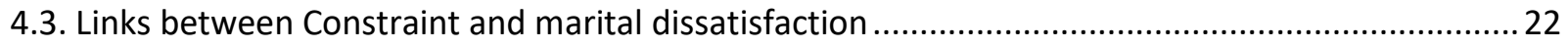

4.4. Links between Openness to Experience and marital dissatisfaction ............................................. 22

4.5. Links between personality disorder characteristics and marital dissatisfaction ...........................23

4.6. Effects of personality on marital dissatisfaction were attenuated in marriages of longer duration

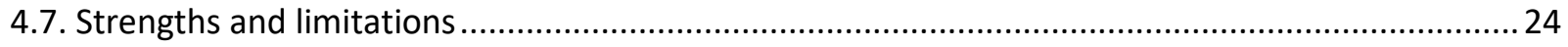

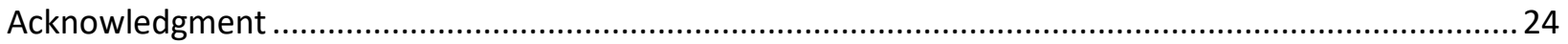

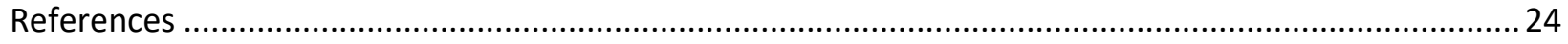

\section{Normal and abnormal personality traits are associated with marital satisfaction for both men and women: An Actor-Partner Interdependence Model analysis}

\section{Catherine B. Stroud}

The Family Institute at Northwestern University, Evanston, IL C. Emily Durbin

The Family Institute at Northwestern University, Evanston, IL Department of Psychology and The Family Institute at Northwestern University, Evanston, IL 


\title{
Seema D. Saigal \\ Department of Psychology, Northwestern University, Evanston, IL Lynne M. Knobloch-Fedders \\ The Family Institute at Northwestern University, Evanston, IL
}

\begin{abstract}
Research has demonstrated associations between relationship satisfaction and personality traits. Using the Actor-Partner Interdependence Model, we explored associations between self-reported relationship satisfaction in couples $(n=118)$ and various measures of normal and abnormal personality, including higher-order dimensions of PE/Extraversion, NE/Neuroticism, Constraint (CON), and their lower-order facets. We also examined gender differences and moderators of associations. Consistent with the Vulnerability Stress Adaptation Model, self- and partner-reported NE and PE were related to satisfaction, and their lower-order traits demonstrated differential associations with satisfaction. Further, abnormal personality traits specific to the interpersonal domain and personality disorder symptoms demonstrated effects. Relationship length emerged as a significant moderator, with associations weakening as relationship duration increased.
\end{abstract}

\section{Keywords}

Personality; Marital satisfaction; Negative Emotionality; Positive Emotionality; Constraint

The broad dimensions of individual differences in emotion, motivation, cognition, and behavior recognized in various structural models of personality (Clark and Watson, 1999, Goldberg, 1993, McCrae and Costa, 1990, Rothbart et al., 2000) each describe consistent patterns or styles of behavior that are either fundamentally interpersonal in nature (e.g., Agreeableness, Extraversion) or which likely shape the content and quality of interactions between individuals and their representations of one another (e.g., Neuroticism). Consistent with this, several higher-order normal personality traits have been linked concurrently and prospectively to relationship functioning across numerous interpersonal relationships, including parent-child (e.g., Kochanska et al., 2004, South et al., 2008), peer/friendship (e.g., Asendorpf and Wilpers, 1998, Graziano et al., 1996), and significant other domains (e.g., Bono et al., 2002, Carver, 1997).

Considerable research has focused on the effects of personality on interpersonal functioning in the domain of couple/marital relationships, with many examining marital dissatisfaction. Karney and Bradbury's (1995) Vulnerability Stress Adaptation Model (VSA) proposed that individual characteristics, such as personality traits, contribute both to stressful experiences encountered by couples as well as to how effectively couples adapt to these experiences. Marital dissatisfaction is seen as resulting from the interplay of personality traits, stressful experiences and adaptive processes, with personality traits indirectly affecting marital dissatisfaction through adaptive processes (marital interactions).

Consistent with the predictions of the VSA model, empirical work has evidenced support for links between personality traits and couple relationship constructs such as marital dissatisfaction. This work has predominately focused on the Big Three (Tellegen, 1985, Watson and Clark, 1992) higher-order 
dimensions of adult personality: Negative Emotionality (NE/Neuroticism, including elements of the Five Factor Model [FFM] Neuroticism and Agreeableness [inversely]), Positive Emotionality (PE/Extraversion, including FFM Extraversion and achieving aspects of Conscientiousness), and Constraint (CON, including controlled aspects of FFM Conscientiousness and elements of Openness to Experience). $\frac{1}{}$ Among these, evidence for NE is particularly strong. High levels of self-reported NE are associated both concurrently and prospectively with lower marital quality and satisfaction (e.g., Caughlin et al., 2000, Donnellan et al., 2004, Karney and Bradbury, 1997, Robins et al., 2000, Robins et al., 2002; see Karney and Bradbury (1995) for a review). In addition, individuals whose partners report high levels of NE also tend to report higher levels of dissatisfaction and lower quality relationships (e.g., Botwin et al., 1997, Donnellan et al., $\underline{2007}$ Robins et al., 2000). Further, links between NE and marital outcomes appear to be bidirectional: not only does NE predict progressively worse relationships over time, but the experience of being in a troubled relationship can lead to increases in NE over time (Robins et al., 2002).

The effects of the higher-order factor of NE on marital satisfaction have been consistently replicated, but most studies have not explored whether these effects are comparable across different lower-order NE traits (e.g., stress reaction, aggression). Of those studies that investigated lower-order traits, two investigations demonstrated similar associations between different NE facets and relationship outcomes (Donnellan et al., 2005, Robins et al., 2000). However, the influence of partners' NE on targets' satisfaction differed as a function of NE subtrait and gender. Partner-reported aggression had the greatest influence on women's dissatisfaction whereas partner-reported alienation and stress reaction had the greatest influence on men's dissatisfaction (Robins et al., 2000). Consistent with findings for alienation and aggression, the FFM trait Agreeableness has evidenced positive associations with marital quality and satisfaction among married couples (Botwin et al., 1997, Donnellan et al., 2004; cf. Watson, Hubbard, \& Wiese, 2000) and negative associations with observed negative interactions (Donnellan et al., 2004). Taken together, these findings suggest that investigating associations between self- and partner-reported NE subtraits as well as gender differences may lead to a more nuanced understanding of the link between NE and dissatisfaction.

In contrast to $\mathrm{NE}$, there has been less research examining Positive Emotionality (PE), despite emerging evidence for its positive association with relationship quality (e.g., Donnellan et al., 2005, Robins et al., 2002). For example, among adult couples, individuals high in PE tend to report more satisfying relationships (Robins et al., 2000, Watson et al., 2000). However, research on the influence of partners' PE on targets' relationship satisfaction has been inconsistent. One investigation found no indication that partners' level of trait positive affectivity influenced targets' relationship satisfaction (Watson et al., 2000) whereas other work suggests that while women's satisfaction may be related to their partners' PE, men's satisfaction is not associated with their partners' PE (Robins et al., 2000). Thus, although some research demonstrates that self-reported PE may be positively related to relationship satisfaction, supporting the VSA model, this trait has been the subject of fewer studies, and the effect of partnerreported PE has rarely been explored.

As for NE, facets of PE may be differentially related to marital satisfaction. For example, Donnellan and colleagues (2007) demonstrated that both self- and partner-reported Communal PE (warmth, sociability, and happiness) were negatively related to targets' dissatisfaction, but Agentic PE (achievement and social potency) was unrelated. Similarly, Robins and colleagues (2000) reported that men's and women's relationship satisfaction were primarily related to their self-reported closeness and well-being, rather than achievement and social potency. In addition, women's satisfaction was also related to their male 
partners' self-reported social closeness and well-being. Thus, it is imperative to examine different aspects of PE in relation to marital satisfaction (Donnellan et al., 2007).

Similar to PE, there is limited evidence that Constraint is associated with relationship satisfaction. For example, individuals who report high levels of Constraint at age 18 exhibit more positive romantic relationship outcomes in young adulthood (Robins et al., 2002). Similarly, positive associations have been identified between self-reported (but not partners' self-reported) Constraint and targets' relationship satisfaction among young adult couples (Donnellan et al., 2007). However, other work suggests that men's, but not women's, Constraint influences both partners' relationship satisfaction (Robins et al., 2000). Associations may also vary for different facets of Constraint. Robins and colleagues (2000) also found women's relationship satisfaction was related to their level of self-control as well as their partners' level of self-control and traditionalism, whereas men's satisfaction was only related to their own level of traditionalism. Further, the Constraint subtrait of harm avoidance appears to be unrelated to satisfaction and quality (Donnellan et al., 2005, Robins et al., 2000).

Similar to the inconclusive findings for Constraint, the few investigations of associations between the FFM trait of Openness to Experience and relationship satisfaction have yielded mixed results. For instance, in one investigation, individuals whose partners reported higher levels of Openness reported higher levels of marital satisfaction (Botwin et al., 1997). In contrast, Watson and colleagues (2000) found that neither individuals' self-reported level of Openness, nor their partners' self-reported Openness, were related to relationship satisfaction. Similarly, Donnellan and colleagues (2004) found no evidence linking Openness to global evaluations of relationship quality and satisfaction; however, it was negatively correlated with observed negative interactions. Absorption, a lower-order trait linked to high Openness, was unrelated to relationship variables in two studies of young adults (Donnellan et al., 2005, Robins et al., 2000). These mixed findings highlight the need for additional research exploring links between Openness and relationship satisfaction.

In the current study, we sought to extend previous research examining the role of personality in relationship satisfaction in a number of ways. First, we investigated both self- and partner-reported personality in relation to targets' relationship satisfaction, and modeled these associations using the Actor-Partner Interdependence Model (APIM; Kashy \& Kenny, 2000). This model accounts for the interdependence of data that exists in couples and permits direct examination of gender differences. Second, in addition to exploring higher-order factors of normal personality (NE, PE, and CON) and their lower-order facets, we also examined abnormal personality traits, as individual differences in problematic personality styles may be even more important to understanding intimate relationships. In spite of research linking frank personality disorders (e.g., Bouchard, Sabourin, Lussier, \& Villeneuve, 2009) and personality disorder symptoms (e.g., South, Turkheimer, \& Oltmanns, 2008) to negative relationship outcomes, research has not examined whether individual differences in abnormal personality traits related to these disorders influence relationship satisfaction. We included measures designed to assess traits related to each of the personality disorders identified in the Diagnostic and Statistical Manual-IV (DSM-IV; American Psychiatric Association, 2000), Clusters A (odd/eccentric), B (dramatic) and $C$ (anxious), as well as measures of personality traits specific to the interpersonal context. Finally, we examined these questions in an ethnically diverse sample of couples who varied in the length of their relationship, but were all the parents of at least one young child. In this way, we expand beyond previous reports that have focused largely on Caucasian young adults and newlyweds. 
Based on previous research on personality predictors of marital dissatisfaction and the predictions of the VSA model, we predicted that: (1) self- and partner-reported NE would be positively related to marital dissatisfaction; (2) self- and partner-reported PE would be negatively related to marital dissatisfaction. Analyses for other normal traits (CON, Openness) were exploratory, as were those examining lower-order personality facets. Given some previous empirical findings indicating gender differences in the association between personality and relationship dissatisfaction (e.g., Robins et al., 2000), we also explored gender differences in our sample. Finally, we predicted that measures of abnormal personality and interpersonal functioning would be as (if not more) strongly associated with marital dissatisfaction than normal traits, given (1) links between personality pathology and relationship problems (Bouchard et al., 2009, South et al., 2008) and (2) evidence that abnormal personality represents extreme variations in normal personality traits (Markon, Krueger, \& Watson, 2005), with traits related to personality disorders and normal FFM and Big Three traits included within a single framework (Watson, Clark, \& Chmielewski, 2008). In all analyses, we utilized the power of the APIM model to test both self (actor) and partner personality traits as predictors of self-reported relationship dissatisfaction.

In addition, we examined several couple level variables that may moderate actor and partner effects of personality traits. The small to moderate effect sizes in the existing literature suggest that personality traits may not be uniformly associated with marital dissatisfaction in the population, but may be more or less related depending upon other characteristics of the individuals or couples. First, we investigated if associations changed as a function of the number of children couples were raising. Although it has been proposed that associations between personality and marital satisfaction may be different in childless marriages as compared to marriages with children (e.g., Karney \& Bradbury, 1995), and research suggests that satisfaction declines across the transition to parenthood (e.g., Lawrence, Rothman, Cobb, Rothman, \& Bradbury, 2008), the impact of number of children on associations between personality and marital satisfaction is unknown. Second, we tested if associations were moderated by family income, using this as a measure of an important relationship stressor. Based on the predictions of the VSA model and research linking economic difficulties to marital dissatisfaction (e.g., Conger, Rueter, \& Elder, 1999), we predicted that family income would moderate associations between personality and marital satisfaction.

Third, we investigated if associations were moderated by relationship duration. Indirect evidence suggests that personality trait-marital satisfaction associations may vary according to relationship duration. First, different traits may be linked to satisfaction for dating versus married couples (Watson et al., 2000). Second, among couples in long-term marriages, FFM personality traits had small (but significant) effects on marital satisfaction for middle-aged, but not older adults, suggesting that the influence of personality may lessen with time (Schmitt, Kliegel, \& Shapiro, 2007). In spite of these suggestive findings, relationship duration did not moderate associations between personality and satisfaction among dating and cohabitating young adult couples (Robins et al., 2002). However, as suggested by the authors, their findings may not generalize to older adults or long-term romantic relationships (such as marriage), compelling a test of the effect of relationship duration in a sample of married couples. 


\section{Method}

\subsection{Participants and procedure}

Heterosexual couples were recruited from the Chicago area using a commercial mailing list, radio and print ads, and internet advertisements for a larger study examining family relationships, temperament, and psychopathology. Families were eligible if they had a biological child between the ages of 3 and 6.5 years and had cohabitated for the duration of that child's lifetime. The larger study included two laboratory visits, one assessing child temperament and the second assessing family interactions (not discussed in this report) and the marital relationship. Families were compensated for their participation. Parent participants who attended the latter visit completed a battery of questionnaires, including measures of normal and abnormal personality and marital dissatisfaction. Of the 168 couples enrolled in the larger study, 118 completed the second visit and were included in the present study. Of the 50 who were not included, 28 couples did provide demographic data. Compared to those who participated in the marital assessment, this subset was raising significantly more children $(p<.05)$, but did not differ on mean age of wives or husbands ( $p s>.05$ ).

Demographics are presented in Table 1 . Couples had a range of $1-5$ children (see Table 1). Most couples were married $(n=109 ; 93.2 \%)$, although a few were living together $(n=3 ; 2.6 \%)$, engaged $(n=2 ; 1.7 \%)$, dating $(n=2 ; 1.7 \%)$ or separated $(n=1 ; .97 \%)$. The mean length of marriage was 8.83 years, with a range of 0.17 to 21 years. If couples were not married, the length of their relationship was used in the analyses. Women were between the ages of 23 and 49, and men were between the ages of 23 and 57. Data on race/ethnicity were provided by $91.5 \%$ of mothers and $89.8 \%$ of fathers as follows: Caucasian/White (75.9\% mothers, $75.5 \%$ fathers), Hispanic/Latino (10.2\% mothers, $11.3 \%$ fathers), African-American/Black (9.3\% mothers, 9.4\% fathers), Asian (8.3\% mothers, $4.7 \%$ fathers), Native American (2.8\% mothers, $1.9 \%$ fathers), other (1.9\%mothers, $4.7 \%$ fathers), and bi- or multi-racial (1.9\% mothers, $3.8 \%$ fathers). Categories do not sum to $100 \%$ as participants could endorse multiple categories. For couples in which both partners reported their ethnicity, $80.4 \%$ reported the same ethnicity and $19.6 \%$ reported different ethnicity. One-hundred and seven couples (86.4\%) self-reported yearly family income (in dollars on a 6 -point scale): $1.9 \%$ reported income less than 10,$000 ; 17.8 \%$ reported income between 21,000 and 40,$000 ; 15.0 \%$ reported income between 41,000 and 60,000; $31.8 \%$ reported income between 61,000 and 100,000 ; and $33.6 \%$ reported income over 100,000.

Table 1. Descriptive statistics for level-1 and level-2 variables.

\section{Scale}

MSI-R

Level-1 variables

$M P Q$

\section{Global distress}

Negative affect

Positive affect

Constraint

Affiliative PE

Agentic PE

Well being
M

.25

SD

.26

100.89

102.89

102.56

.74

1.01

.76 


\begin{tabular}{|c|c|c|c|}
\hline \multirow{2}{*}{$\begin{array}{l}\text { Scale } \\
\text { MSI-R }\end{array}$} & & $M$ & SD \\
\hline & Global distress & .25 & .26 \\
\hline & Social closeness & .72 & .19 \\
\hline & Achievement & .58 & .21 \\
\hline & Social potency & .44 & .24 \\
\hline & Stress reaction & .37 & .26 \\
\hline & Alienation & .11 & .17 \\
\hline & Aggression & .23 & .18 \\
\hline & Absorption & .44 & .22 \\
\hline & Control & .68 & .20 \\
\hline & Traditionalism & .57 & .19 \\
\hline & Harm avoidance & .71 & .18 \\
\hline \multirow[t]{15}{*}{ SNAP } & Negative Temperament & 2.86 & 1.12 \\
\hline & Positive Temperament & 4.25 & .98 \\
\hline & Disinhibition & 2.33 & .92 \\
\hline & Manipulation & 2.06 & .85 \\
\hline & Mistrust & 2.27 & 1.10 \\
\hline & Self-harm & 1.70 & .86 \\
\hline & Aggression & 2.36 & 1.02 \\
\hline & Eccentric Perceptions & 1.88 & 1.22 \\
\hline & Dependency & 3.16 & 1.19 \\
\hline & Entitlement & 2.76 & 1.07 \\
\hline & Exhibitionism & 3.09 & 1.30 \\
\hline & Detachment & 2.71 & 1.02 \\
\hline & Impulsivity & 2.70 & .96 \\
\hline & Propriety & 4.17 & 1.11 \\
\hline & Workaholism & 3.42 & 1.04 \\
\hline \multirow[t]{6}{*}{ IIP } & Domineering & .80 & .65 \\
\hline & Cold & .71 & .62 \\
\hline & Vindictive & .73 & .60 \\
\hline & Socially avoidant & .99 & .75 \\
\hline & Nonassertive & 1.32 & .84 \\
\hline & Exploitable & 1.28 & .70 \\
\hline
\end{tabular}




\begin{tabular}{|c|c|c|c|}
\hline Scale & & $M$ & SD \\
\hline \multirow[t]{3}{*}{ MSI-R } & Global distress & .25 & .26 \\
\hline & Overly nurturant & 1.37 & .71 \\
\hline & Intrusive & .97 & .64 \\
\hline \multirow[t]{10}{*}{ IPDE screener } & Paranoid & 1.31 & 1.22 \\
\hline & Schizoid & 1.19 & 1.11 \\
\hline & Schizotypal & 1.22 & 1.37 \\
\hline & Antisocial & .66 & 1.11 \\
\hline & Borderline & 1.57 & 1.70 \\
\hline & Histrionic & 2.17 & 1.55 \\
\hline & Avoidant & 2.51 & 2.09 \\
\hline & Dependent & 2.30 & 1.45 \\
\hline & OCPD & 2.52 & 1.80 \\
\hline & Total disorders & 18.55 & 9.16 \\
\hline \multicolumn{4}{|c|}{ Level-2 variables } \\
\hline & Length of marriage & 8.81 & 3.96 \\
\hline & Number of children & 2.32 & .88 \\
\hline & Wives' age & 36.91 & 5.17 \\
\hline & Husbands' age & 38.27 & 5.79 \\
\hline
\end{tabular}

Notes: MSI-R = Marital Satisfaction Inventory-Revised. MPQ = Multidimensional Personality Questionnaire. SNAP $=$ Schedule for Nonadaptive and Adaptive Personality Self-Description Rating Form. PE $=$ Positive Emotionality. IIP = Inventory of Interpersonal Problems. IPDE = International Personality Disorders Examination.

\section{Measures}

\subsection{Marital satisfaction}

Participants completed the Marital Satisfaction Inventory-Revised (MSI-R; Snyder \& Aikman, 1999), a 150 item true-false self-report measure of marital adjustment. The MSI-R has 10 subscales assessing specific areas of relationship distress, one global distress scale, and two validity scales. We used the 22item global distress scale in all analyses ( $\alpha \mathrm{s}=.99$ for both women and men); higher scores indicate higher levels of dissatisfaction. The MSI-R has demonstrated good internal consistency, test-retest reliability and discriminant validity (Snyder \& Aikman, 1999).

\subsection{Personality measures}

\subsubsection{Multidimensional Personality Questionnaire}

The Multidimensional Personality Questionnaire (MPQ; Patrick, Curtin, \& Tellegen, 2002) is a 300 item self-report questionnaire that assesses three broad personality dimensions: Positive Emotionality (PE), Negative Emotionality (NE), and Constraint (CON). Each higher-order dimension is marked by the following lower order scales: (a) PE: Wellbeing, Social Potency, Achievement, Social Closeness; (b) NE: 
Stress Reaction, Alienation, Aggression; and (c) CON: Contro1, Harm Avoidance, Traditionalism. The MPQ also includes a subscale labeled Absorption, which is related to Openness to Experience. Internal consistency reliabilities for all scales were in the moderate to high range ( $\alpha$ s $=.73-.90$ ).

\subsubsection{Schedule for Nonadaptive and Adaptive Personality Self-Description Rating Form}

The Schedule for Nonadaptive and Adaptive Personality Self-Description Rating Form (SNAP-SRF; Harlan \& Clark, 1999) is a measure of both normal and abnormal personality traits relevant to personality disorders. The SNAP-SRF includes 33 items consisting of paragraph descriptors of individuals that are low versus high on the characteristic of interest; items are rated on a 6-point Likert scale. It consists of 15 primary traits tapping normal and abnormal personality traits, grouped into three higher-order categories: Negative Temperament comprises the lower-order traits of Mistrust, Manipulation, Aggression, Self-Harm, Dependency, and Negative Temperament; Positive Temperament comprises Exhibitionism, Entitlement, Detachment (reverse-scored), and Positive Temperament; and Disinhibition includes Impulsivity, Propriety (reverse-scored), Workaholism (reverse-scored), and Disinhibition. It also includes a single item tapping Eccentric Perceptions, which is conceptually related to Openness to Experience. Each scale contains 2-3 items, with the exception of Eccentric Perceptions. Alphas were in the acceptable to low range $(.19-.81$; median $=.59)$ and were similar to those reported by Harlan and Clark (1999).

\subsubsection{Inventory of Interpersonal Problems}

The circumplex version of the Inventory of Interpersonal Problems (IIP; Horowitz, Rosenberg, Baer, Ureno, \& Villasenor, 1988) assesses personality traits specific to the interpersonal domain defined by two dimensions, agency (ranging from control to submission) and communion (friendliness to hostility). The IIP has nine subscales, including: vindictive, cold, domineering, intrusive, socially avoidant, nonassertive, exploitable and overly nurturant interpersonal styles (all $\alpha s=.99$ ). The IIP scales mostly appeared to tap NE in our sample; their mean correlations with MPQ scales were as follows: with NE, $|r|=.34$; with PE; $|r|=.18$; with CON; $|r|=.11$. The socially avoidant and nonassertive scales also had weak relationships to PE. The IIP has demonstrated good test-retest reliability, validity and circular structure (Horowitz et al., 1988).

\subsubsection{International Personality Disorders Examination Screener}

The International Personality Disorder Examination Screener (IPDE Screener; Loranger \& et al., 1994) is a 77 item self-report true-false questionnaire based on the IPDE clinician-administered interview to assess symptoms of DSM-IV personality disorders. The IPDE includes 10 subscales measuring the three Clusters: (1) Cluster A: Paranoid, Schizoid, Schizotypal; (2) Cluster B: Antisocial, Borderline, Histrionic, Narcissistic; and (3) Cluster C: Avoidant, Dependent, Obsessive-Compulsive (OCPD). The total number of items related to each of the subscales was summed ( $\alpha s=.22-.73$; median $=.54), \underline{3}$ and we also summed the scores on all of the traits to reflect the total number of personality disorder characteristics.

\subsection{Data analyses}

Multilevel modeling (MLM) using the Actor-Partner Interdependence Model for distinguishable dyads (APIM; Kashy \& Kenny, 2000) was used to test associations between personality and marital dissatisfaction while accounting for the nested (individuals within couples) structure of the data. In this model, "actor effects" refer to associations between personality traits and marital satisfaction within a person (i.e., between partner A's self-reported personality and partner A's self-reported marital dissatisfaction). "Partner effects" quantify associations across spouses: that is, the effect of partner B's 
self-reported personality on partner A's marital dissatisfaction (and vice versa). Marital dissatisfaction was the dependent variable, individual level predictors (i.e., self- and partner-reported personality traits) were explored at level-1, and couple level variables (e.g., relationship duration) were explored at level-2. All analyses were conducted with HLM 6.06, using full maximum likelihood estimation.

Analyses proceeded in a series of steps. First, an unconditional means models (including only an intercept term) was conducted to quantify individual differences in marital dissatisfaction and to provide a baseline against which to evaluate subsequent models. Next, we conducted a model adding the effects of gender. Finally, the effects of personality traits of actors and partners and their interactions with gender (level-1) were added to the model (each trait entered separately). Finally, we conducted an additional model incorporating different combinations of significant level-1 predictors in the same model to explore which remained significant after accounting for the other predictors.

MLM yields two sets of informative statistics, fixed effects (sample estimates for the intercept and level1 predictors), and variance components (estimates of the degree of individual differences in each predictor effect). Models can be run with estimation of variance components or without (by fixing the variances for parameters). Significant variance components for level-1 parameters suggest that predictors of these effects can be explored at level-2. APIM equations are limited in the number of parameters that can be estimated simultaneously. Therefore, to examine the robustness of our findings, for each level-1 predictor explored, we conducted analyses twice: first, allowing the variance component for the actor effect to vary while fixing the variance components of the other effects; and second, allowing the variance component on the partner effect to vary while fixing the variance components of the other effects.

If the actor and/or partner effects were significant, models incorporating level-2 predictors of these effects (and of the intercept term) were subsequently tested. We examined the following predictors: the couples' number of children, family income, and length of marriage. In these models, we allowed the variance component of the intercept to vary and fixed the variance components of the other effects. Because there are known developmental changes in personality traits across adulthood (Caspi, Roberts, \& Shiner, 2005), earlier age of marriage is related to negative marital outcomes (e.g., Kinnunen \& Pulkkinen, 2003), and length of marriage was significantly correlated with age (.47 for men and .54 for women; ps <.05), when length of marriage was a significant predictor of the actor or partner effect, we added participants' age as a level-2 predictor to rule out the possibility that age was driving the effect of length of marriage. Finally, if more than one level-2 predictor was significant for the same level-1effect, we computed an additional model incorporating all significant level-2 predictors in the same model to explore which predictors remained significant after accounting for the other predictors.

\section{Results}

\subsection{Unconditional means model}

Individuals differed significantly on their level of marital dissatisfaction, as the variance component for the intercept was significant (intercept fixed effect $=0.25[0.03], p<.01$; intercept variance component $=0.057, p<.01)$. 


\subsection{Effects of negative emotionality on marital dissatisfaction}

As shown in Table 2, as predicted, the actor effects for higher-order NE factors (MPQ NA and SNAP NT) were each significantly associated with marital dissatisfaction $(p<.01)$; participants with higher NE reported higher levels of marital dissatisfaction. The partner effects for the NE factors were also significantly associated with marital dissatisfaction $(p<.01)$, such that partners' self-reported NE was positively related to their spouses' marital dissatisfaction. The actor effect for NT was qualified by a significant gender interaction $(t[123]=-2.01, p<.05)$, indicating that the positive association between self-reported NT and marital dissatisfaction was stronger among wives. None of the other gender interactions were significant. All of the variance components were significant ( $p s<.01$ ), indicating significant individual differences in the actor and partner effects that could be explained by level- 2 predictors.

Table 2. Actor-Partner Independence Models for the Higher-Order factors of Negative Emotionality, Positive Emotionality and Constraint.

\begin{tabular}{|c|c|c|c|c|c|c|}
\hline \multirow{3}{*}{ Scale } & \multicolumn{2}{|c|}{ Negative Emotionality } & \multicolumn{2}{|c|}{ Positive Emotionality } & \multicolumn{2}{|l|}{ Constraint } \\
\hline & \multicolumn{2}{|l|}{ MPQ NE } & \multicolumn{2}{|l|}{ MPQ PE } & \multicolumn{2}{|c|}{ MPQ Constraint } \\
\hline & P effect fixed & A effect fixed & $\begin{array}{l}\text { P effect } \\
\text { fixed }\end{array}$ & A effect fixed & $\begin{array}{l}\text { P effect } \\
\text { fixed }\end{array}$ & A effect fixed \\
\hline $\begin{array}{l}\text { Fixed effects: intercept } \\
\text { (SE) }\end{array}$ & $\begin{array}{l}-22.10 \\
(3.53)^{* *}\end{array}$ & $-22.13(3.52)^{* *}$ & ${ }^{*} 10.40(6.00)^{ \pm}$ & $10.42(6.01)^{ \pm}$ & $-.90(5.80)$ & $-.74(5.84)$ \\
\hline Gender & $.03(.01)^{* *}$ & $.03(.01)^{* *}$ & $.03(.01)^{* *}$ & $.03(.01)^{* *}$ & $.03(.01)^{* *}$ & $.03(.01)^{* *}$ \\
\hline Actor & $.12(.02)^{* *}$ & $.12(.02)^{* *}$ & $-.05(.02)^{* *}$ & $-.05(.03)$ & $.00(.02)$ & $-.01(.03)$ \\
\hline Partner & $.10(.02)^{* *}$ & $.10(.02)^{* *}$ & $-.05(.02)^{* *}$ & $-.05(.03)^{ \pm}$ & $.02(.02)$ & $.02(.03)$ \\
\hline \multicolumn{7}{|l|}{ Variance components } \\
\hline Level-1 within person & .01119 & .01119 & .01126 & .01131 & .01118 & .01124 \\
\hline Actor & $.00000^{* *}$ & - & $.00001^{* *}$ & - & $.00001 * *$ & - \\
\hline Partner & - & $.00000 * *$ & - & $.00001 * *$ & - & $.00001 * *$ \\
\hline Deviance (df) & $-115.37(99)$ & $-115.36(99)$ & $-82.18(99)$ & $-81.77(99)$ & $-79.30(99)$ & $-78.85(99)$ \\
\hline \multirow[t]{2}{*}{ Scale: } & SNAP NT & & SNAP PT & & SNAP DI & \\
\hline & PE Fixed & AE Fixed & PE Fixed & AE Fixed & PE Fixed & AE Fixed \\
\hline $\begin{array}{l}\text { Fixed effects: Intercept } \\
\text { (SE) }\end{array}$ & $-.05(.08)$ & $-.08(.09)$ & $.94(.25)^{* *}$ & $.86(.25)^{* *}$ & $.03(0.13)$ & $.01(0.12)$ \\
\hline
\end{tabular}




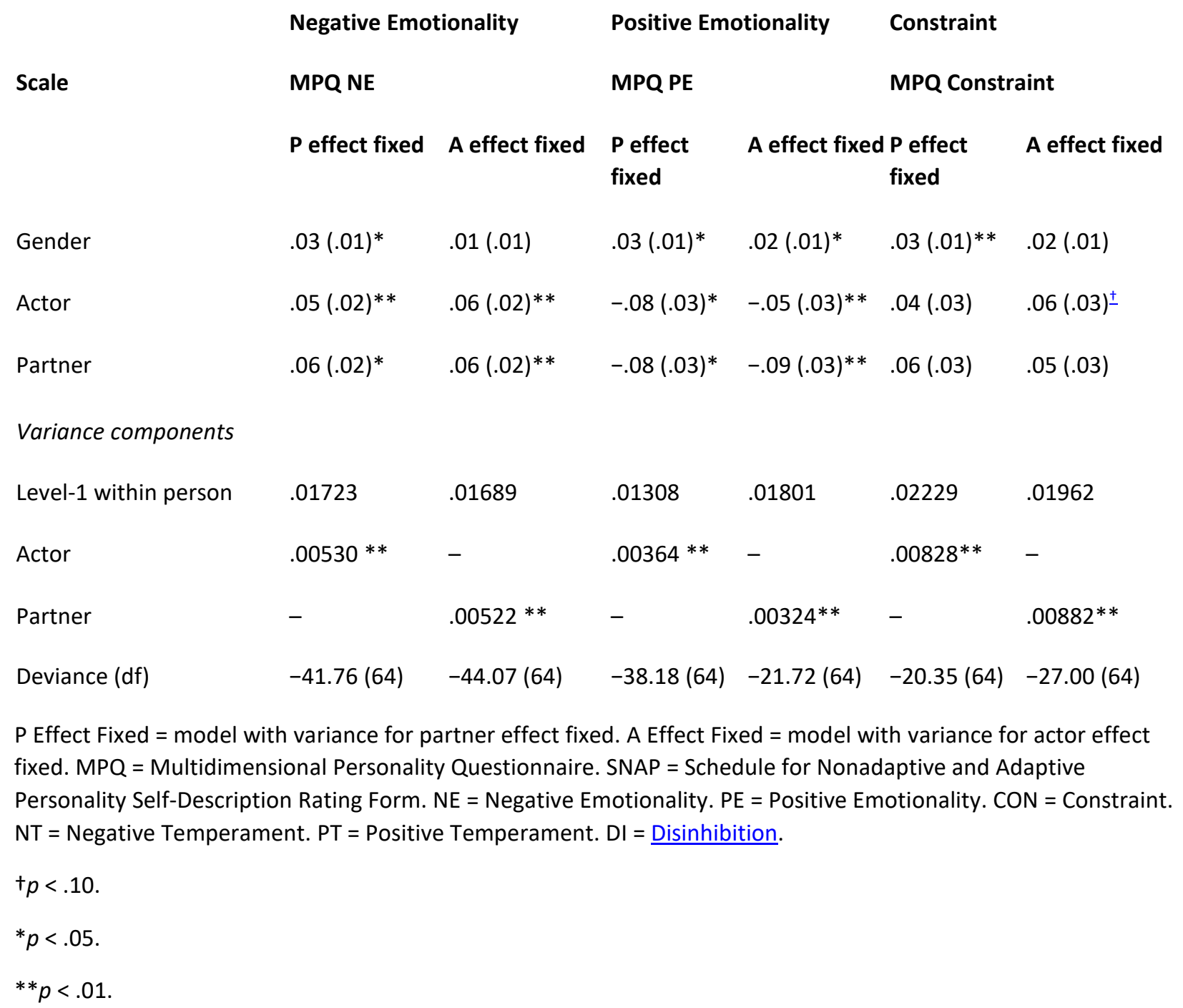

In models incorporating level-2 predictors (see Table 3), neither number of children or family income was a significant predictor of either the actor or partner effects for NE variables. However, length of marriage significantly predicted individual differences in most of the actor and partner effects, including the actor effect for NA $(p<.01)$, the partner effect for NA $(p<.01)$ and the partner effect for NT $(p<.05)$. In all cases, the positive association between NE and marital dissatisfaction weakened as the years of marriage increased. Examining the estimates for these effects revealed that the effects of NE on marital dissatisfaction appear to be strongest among participants married less than 12 years. All of these effects for marriage duration held when controlling for age at level-2.

Table 3. Actor-Partner Independence Models for the Higher-Order traits incorporating level-2 predictors.

\begin{tabular}{|c|c|c|c|c|c|c|}
\hline Level-2 predictor & Number of & nildren & Family income & & Average lengt & \\
\hline Scale & MPQ NE & SNAP NT & MPQ NE & SNAP NT & MPQ NE & SNAP NT \\
\hline Negative Emotionality & & & & & & \\
\hline Fixed effects: intercept (SE) & $-16.22(9.8$ & $-.12(.32)$ & $-27.20(12.93)^{*}$ & $.14(.46)$ & $-37.21(7.60)^{*}$ & ${ }^{k}-.21(.27)$ \\
\hline
\end{tabular}




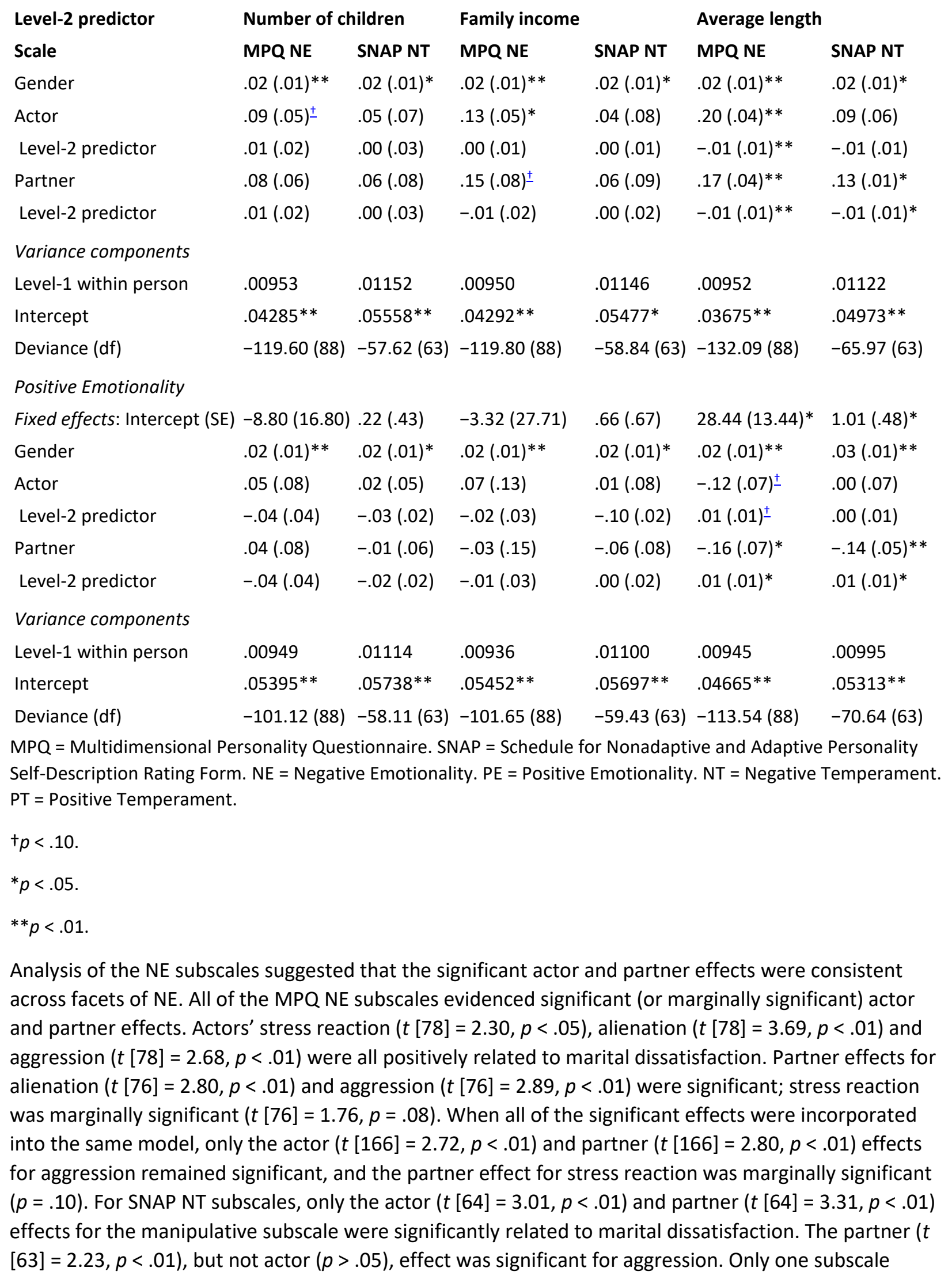


interacted with gender. The partner effect for self-harm interacted with gender $(t[124]=1.96, p<.05)$, such that the positive association between partners' self-harm and marital dissatisfaction was stronger among wives than husbands. When all of the significant effects for the SNAP NE scales were incorporated into the same model, only the actor $(t[123]=3.50, p<.01)$ and partner $(t[123]=3.31$, $p<.01)$ effects for the manipulative subscale remained significant.

Models incorporating level-2 predictors of actor and partner effects for NE subscales were largely consistent with the findings for the NE higher-order factors. Marriage length emerged as a significant predictor of both the actor and partner effects for stress reaction and aggression as well as the actor effect for alienation. Similarly, for SNAP subscales, marriage length was a significant predictor of both actor and partner effects for manipulativeness and the partner effect for aggression. In all cases, the actor and partner effects were attenuated as the length of marriage increased. These effects remained significant when controlling for age, with the exception of those for stress reaction and manipulativeness ( $p=.12$ for both). Number of children and family income were unrelated to NE subscale actor and partner effects, with one exception. Family income was a significant predictor of the partner effect for MPQ aggression, such that its association with marital dissatisfaction weakened as family income increased. However, when both family income and marriage length were included as level-2 predictors of the partner effect, only marriage length remained significant.

In sum, there are significant positive associations between participants' level of marital dissatisfaction and their own and their partners' self-reported NE. The higher-order effects of NE were driven by its stress reaction, alienation, aggression and manipulative components. The strength of most associations were predicted by the length of the marriage, such that the actor and partner effects of NE on marital dissatisfaction were attenuated among couples with longer relationship duration.

\subsection{Effects of positive emotionality on marital dissatisfaction}

As predicted, there were significant actor effects for higher order PE factors (MPQ PE, SNAP PT) on marital dissatisfaction ( $p s<.05$ ); low PE was associated with greater marital dissatisfaction (see Table 2). Partner PE was also negatively related to marital dissatisfaction (significantly $[p<.01]$ for PT, and marginally $[p=.09]$ for PE). However, for both the SNAP and MPQ scales, when the actor and partner effects for PE and NE were included in the same model, PE effects were no longer significant (although the NE effects were significant). Gender did not interact with either actor or partner PE effects, indicating similar effects for husbands and wives. There were significant individual differences in the magnitude of both actor and partner effects.

In models incorporating level-2 predictors of PE effects, number of children and family income were not significant (Table 3 ). However, length of marriage predicted individual differences in partner effects for both PE and PT ( $p s<.05)$, and was marginally associated with the actor effect for PE $(p=.08)$. For both actor and partner $P E$, their negative associations with marital dissatisfaction weakened as marriage length increased; the strongest effects of PE were in the first 12 years of marriage. These effects held when controlling for age at level-2.

Analysis of the subscales suggests that actor and partner effects for higher-order scales masked differential associations for facets of PE. The MPQ PE scale includes two subscales tapping agentic (achievement and social potency) and communal/affiliative aspects of PE (well-being, social closeness). For affiliative PE, there were negative actor effects for well-being $(t[78]=-4.53, p<.01)$ and social 
closeness $(t[78]=-2.76, p<.01)$, whereas social potency was positively related to dissatisfaction, $t$ $(78)=3.12, p<.01$. For partner effects, well-being $(t[76]=-3.59, p<.01)$ and social closeness $(t$ $[76]=-2.37, p<.05)$ were significant, but social potency was not. The actor and partner effects for achievement were not significant. When all of the significant effects were incorporated in the same model, all remained significant ( $p s<.05$ ) except for partner effect for social closeness $(p=.21)$. However, when the significant effects for the MPQ NE subscales were added to this model, none of the $P E$ subscales were significant, but the actor and partner effects for aggression remained significant. For SNAP PT subscales, only the partner effect for entitlement was significant $(t[64]=2.49, p<.05)$, and it remained so when accounting for the significant NT subscales. None of the gender interactions for PE subscales were significant ( $p s>.05)$.

In models examining level-2 predictors of PE subscale actor and partner effects, length of marriage emerged as a significant predictor for the actor and partner effects for well-being and the actor effect for social closeness, but none of the other effects. In all cases, the effects were attenuated as the length of marriage increased. However, length of marriage no longer predicted the actor effects for well-being or social closeness ( $p s=.12$ ) when controlling for age. Family income was not a significant level-2 predictor of any of the level-1 effects. Number of children predicted individual differences in the actor effect for social closeness, such that the negative association between participants' self-reported social closeness and marital dissatisfaction was stronger for couples with more children, but it was no longer significant when both number of children and length of the marriage were included as level-2 predictors of the partner effect.

In sum, there were significant negative associations between participants' level of marital dissatisfaction and both self- and partner-reported PE, particularly the well-being and social closeness components of this trait. In contrast, there was a positive association between participants' self-reported social potency and marital dissatisfaction; this effect did not attenuate as marriage length increased. Most of the significant effects held when controlling for the other effects, suggesting that the well-being, social closeness and social potency components of PE all uniquely contribute to individual differences in marital satisfaction. Some of these associations were moderated by the length of the marriage, such that the actor and partner effects of PE on marital dissatisfaction were attenuated among couples with a longer relationship history.

\subsection{Effects of Constraint on marital dissatisfaction}

The actor and partner effects for the higher-order factor of Constraint, as assessed by the MPQ, were not significant. Similarly, for the SNAP Disinhibition scale, the partner effect was nonsignificant. However, the actor effect was positive and marginally significant $(p=.07)$. Length of marriage (but not number of children or family income) was a significant level-2 predictor of the actor effect for Disinhibition ( $t$ [123] $=-2.72, p<.01)$, and this effect held when controlling for age. Examining the residuals for the partner effect suggested that the effect of Disinhibition on marital dissatisfaction was strongest among couples married 12 years or less. Gender did not interact with any actor or partner Constraint effects.

Two SNAP Disinhibition subscales demonstrated significant actor and partner effects. Actor ( $t$ $[64]=2.31, p<.05)$ and partner $(t[64]=2.60, p<.05)$ impulsivity were both positively related to dissatisfaction. These effects were moderated by gender (for the actor effect, $t(124)=-1.70, p=.09$; for the partner effect, $t(124)=2.00, p=.05)$. Decomposing the interactions revealed that the positive 
association between actor impulsivity and dissatisfaction was stronger among husbands than wives. In contrast, the partner effect of impulsivity was stronger among wives than husbands. Taken together, this suggests that the effects of impulsivity on marital dissatisfaction are limited to male partners' level of this trait. Similarly, the actor $(t[64]=-3.30, p<.01)$ and partner $(t[64]=-2.62, p<.05)$ effects for propriety were significant, with lower propriety related to higher dissatisfaction. When the significant effects for impulsivity and propriety were incorporated into the same model, all effects remained significant.

In models incorporating level-2 predictors of Disinhibition subscales, length of marriage emerged as a significant predictor in many models. It predicted the actor (but not the partner) effect for propriety at a trend level $(t[121]=1.91, p=.06)$, but was no longer significant when controlling for age. For impulsivity, length of marriage and family income both predicted individual differences in the actor and partner effects. For length of marriage, the effect of impulsivity was attenuated in couples who had been married longer (for the actor effect: $t[123]=-2.00, p<.05$; for the partner effect: $t[151]=-2.12$, $p<.05)$; both effects remained significant when controlling for age. Similarly, the impact of impulsivity was weaker for families at higher levels of income (for the actor effect: $t[123]=-2.01, p<.05$; for the partner effect: $t[151]=-2.56, p<.05)$. When both length of marriage and family income were included as predictors of the actor effect, only length of marriage remained significant ( $t[61]=-3.01, p<.01)$.

The MPQ subscales related to Constraint (control, traditionalism and harm avoidance) did not evidence significant actor or partner effects ( $p s>.05$ ), and only one (control) interacted with gender. This interaction was significant for the actor $(t[168]=2.34, p<.05)$ and partner $(t[168]=-2.58, p<.05)$ effects. For the actor effect, the positive association between control and marital dissatisfaction was stronger for wives than husbands. However, for the partner effect, the association was stronger for husbands than wives. Thus, women's, but not men's, level of control was related to both partners' marital dissatisfaction.

In general, associations between Constraint measures and marital dissatisfaction were weak. Only three subscales relevant to this trait (impulsivity, propriety, and control) emerged as level-1 predictors, while the higher-order scales were not. Several of these effects were moderated by gender, number of years of marriage, and family income.

\subsection{Unique effects of Negative Emotionality, Positive Emotionality, and Constraint}

We added different measures of the higher-order traits and their subscales to the same model to test whether they remained significant (unique) predictors of dissatisfaction after accounting for the effects of other personality traits. When the higher-order factors from the MPQ scales were included in the same model, the actor and partner effects for NE remained significant, the CON effects were marginal ( $p s<.10)$, and the PE effects were no longer significant. Similarly, when the higher-order factors for the SNAP were included in the same model, only the NT effects were significant.

\subsection{Effects of Openness to Experience on marital dissatisfaction}

We collected two measures relevant to Openness to Experience: Absorption (MPQ) and Eccentric Perceptions (SNAP). The actor effects for both absorption $(t[78]=2.14, p<.05)$ and Eccentric Perceptions $(t[64]=2.04, p<.05)$ were positive. The partner effect for Eccentric Perceptions was also significant $(t[64]=2.10, p<.05)$, but that for absorption was not. None of these effects were moderated by gender. Of all the level-2 predictors examined, only one effect was significant. Length of 
marriage moderated the actor effect for absorption at a trend level $(t[151]=-1.75, p=.07)$, and was significant $(t[73]=-2.53, p=.01$ ) when age was also entered as a level-2 predictor (see also Table 4). Thus, abnormal components of Openness were positively related to higher marital dissatisfaction for both men and women.

Table 4. Significant effects for scales related to Negative Emotionality, Positive Emotionality, Constraint and Openness to Experience.
NE
PE
Constraint
Openness to experience

Factors

$\begin{array}{rllll}\text { Actor effects } & \text { NE (MPQ) } & \text { PT (SNAP) } \underline{\underline{b}} & \text { None } & \text { None tested } \\ \text { NT (SNAP) } & & \text { Significant } & \\ \text { Partner effects NE (MPQ) } & \text { PE (MPQ })^{ \pm} & \text {None significant } & \text { None tested } \\ \text { NT (SNAP) } & \text { PT(SNAP) } & & \end{array}$

Subscales

Actor effects Stress Reaction (MPQ) Affiliative PE (MPQ) Impulsivity (SNAP) Absorption (MPQ)

Alienation (MPQ) Wellbeing (MPQ) Propriety (SNAP) Eccentric perceptions (SNAP)

Aggression (MPQ) Social closeness (MPQ)

Manipulation (SNAP) Social Potency (MPQ) $\underline{d}$

Partner effects Stress reaction (MPQ) ${ }^{ \pm, a}$ Affiliative PE (MPQ) Impulsivity (SNAP) Eccentric perceptions (SNAP)

$\begin{array}{ll}\text { Alienation (MPQ) } & \text { Wellbeing (MPQ) } \\ \text { Aggression (MPQ) } & \text { Social closeness (MPQ) Propriety (SNAP) } \\ \text { Manipulation (SNAP) } & \text { Entitlement (SNAP) } \stackrel{a}{ } \\ \text { Aggression (SNAP) } & \text { Detachment (SNAP) })^{ \pm} \\ \text {Self-harm (SNAP) } \underline{\underline{d}} & \end{array}$


$\mathrm{MPQ}=$ Multidimensional Personality Questionnaire. SNAP = Schedule for Nonadaptive and Adaptive Personality Self-Description Rating Form. NE $=$ Negative Emotionality. $\mathrm{PE}=$ Positive Emotionality. NT $=$ Negative Temperament. PT = Positive Temperament.

$c=$ Significant when actor effect is fixed.

$+p<.10$.

aMarginally significant when partner effect is fixed.

bMarginally significant when actor effect is fixed.

dNot significant when actor effect is fixed.

\subsection{Effects of personality traits related to interpersonal functioning on marital dissatisfaction}

Many of the strongest effects for normal personality traits on marital dissatisfaction reviewed above were for lower-order traits tapping interpersonal aspects of those traits (e.g., aggression for NE, social closeness for PE). Consistent with this, several of the domains of problematic interpersonal functioning, as assessed by the IIP, evidenced significant actor and partner effects, including the actor $(t[88]=3.87$, $p<.01)$ and partner $(t[88]=3.03, p<.01)$ effects for vindictiveness, actor $(t[88]=3.95, p<.01)$ and partner $(t[88]=2.68, p<.01)$ effects for interpersonal coldness, actor $(t[88]=2.90, p<.01)$ and partner $(t[88]=2.69, p<.01)$ effects for intrusiveness, and actor $(t[88]=4.08, p<.01)$ and partner $(t$ $[88]=2.28, p<.05)$ effects for overly nurturant. The actor effect for domineering was significant $(t$ $[88]=2.34, p<.05)$, but its partner effect was only marginally significant $(t[88]=1.73, p=.08)$. None of the effects interacted with gender. Actor and partner effects for the socially avoidant, nonassertive, and exploitable scales were not significant. When all the significant effects were included in the same model, only the actor effects for vindictive $(p<.01)$, cold $(p<.05)$ and overly nurturant $(p<.01)$, as well as the partner effect for vindictive $(p<.01)$ remained significant. This suggests that individual differences in interpersonal styles, particularly those characterized by hostility or overly solicitous behavior, are associated with both one's own and one's partners' marital dissatisfaction.

Regarding level-2 predictors of these effects, relationship length predicted individual differences in the actor $(t[171]=-3.06, p<.01)$ and partner $(t[173]=-3.18, p<.01)$ effects for domineering, the actor effect for intrusiveness ( $t$ [171] $=-2.24, p<.05)$, and the partner effect for overly nurturant $(t$ $[171]=-2.47, p<.05)$. It was marginally related for the actor effect for overly nurturant $(t[171]=-1.91$, $p=.06)$. For all traits, the strength of the effects attenuated as the length of marriage increased, and the effects held after controlling for age. Number of children was also a significant predictor of the actor effect for overly nurturant ( $t[171]=-2.86, p<.01$ ); the positive association between the overly nurturant style and marital dissatisfaction was weaker among couples raising more children. When both length of marriage and number of children were included as level-2 predictors of the actor effect for overly nurturant, length of marriage was significant $(t[82]=-2.15, p<.05)$, but number of children was not. The actor and partner effects for the vindictiveness and coldness scales were not moderated by any level-2 predictors.

\subsection{Effects of total personality disorder characteristics on marital dissatisfaction} The actor $(t[89]=5.39, p<.01)$ and partner $(t[89]=3.42, p<.01)$ effects for total disorder characteristics, as measured by the total IPDE screener score, were both significant and positive. Length 
of marriage was associated with individual differences in both the actor $(t[173]=-2.97, p<.01)$ and partner $(t[173]=-2.92, p<.01)$ effects, and its effects held even when controlling for age. None of the other level-2 variables were significant ( $p s>.05$ ), nor were any of the level-1 interactions with gender, suggesting similar effects for husbands and wives.

\subsection{Cluster A personality disorder characteristics}

With one exception, the actor and partner effects for Cluster A personality disorder characteristics (as assessed by the IPDE screener) were all significantly and positively associated with marital dissatisfaction. Significant effects included: actor $(t[89]=2.50, p<.05)$ and partner $(t[89]=3.07$, $p<.01)$ effects for schizoid, and actor $(t[89]=2.78, p<.01)$ and partner $(t[89]=2.01, p<.05)$ effects for schizotypal. The actor effect for paranoid was significant ( $t[89]=3.38, p<.01$ ), but the partner effect was marginal ( $t[89]=1.72, p=.09$ ). None of these effects interacted with gender (see Table 4 ). When all of the significant effects for Cluster $A$ were included in the same model, actor and partner effects for paranoid $(p<.05)$ remained significant, the partner effect for schizoid was marginal $(p=.10)$, and the schizotypal effects were no longer significant.

There were few significant level-2 predictors of individual differences in the effects of Cluster $A$ traits on marital dissatisfaction. Length of marriage was significantly associated with the actor effect for schizoid $(t[173]=-2.00, p=.05)$ and actor $(t[173]=-2.92, p<.01)$ and partner $(t[173]=-3.29, p<.01)$ effects for paranoid. All of these effects held when controlling for age. For schizotypal, number of children emerged as a significant predictor for the actor effect $(t[173]=2.45, p<.05)$, such that the positive association between self-reported schizotypal traits and marital dissatisfaction was weaker for parents with more children.

\subsection{Cluster B personality disorder characteristics}

Similar to findings for Cluster $A$, most of the Cluster $B$ disorders had positive actor and partner effects on marital dissatisfaction. These included: actor $(t[89]=3.44, p<.01)$ and partner $(t[89]=2.91, p<.01)$ effects for antisocial; actor $(t[89]=4.21, p<.01)$ and partner $(t[89]=3.40, p<.01)$ effects for borderline; and actor $(t[89]=2.79, p<.01)$ and partner $(t[89]=2.55, p=.01)$ for histrionic. None of the Cluster B measures interacted with gender (see Table 4). When all of the significant predictors were incorporated in the same model, only the actor effects for antisocial and borderline were significant, their partner effects were marginal (for antisocial, $p=.07$; for borderline, $p=.09$ ) and the effects for histrionic were no longer significant.

Length of marriage predicted individual differences in some of these effects; consistent with other results, as length of marriage increased, actor and partner effects were attenuated, even when controlling for age. This was the case for the actor $(t[173]=3.21, p<.01)$ and partner $(t[173]=-3.56$, $p<.01)$ effects for antisocial, and actor $(t[173]=-3.93, p<.01)$ and partner $(t[173]=-4.57, p<.01)$ effects for borderline. Length of marriage was not a significant predictor for histrionic, but family income was associated with its actor effect $(t[173]=-2.05, p<.05)$. The positive association between selfreported histrionic personality traits and marital dissatisfaction weakened as the level of income increased.

\subsection{Cluster $\mathrm{C}$ personality disorder characteristics}

Many of the Cluster $C$ traits evidenced significant effects. The actor $(t[89]=3.13, p<.01)$ and partner $(t$ $[89]=2.87, p<.01)$ effects for dependent, and actor $(t[88]=4.83, p<.01)$ and partner $(t[88]=2.52$, 
$p<.05)$ effects for OCPD were significant. All effects, except the partner effect for OCPD, remained significant when all were incorporated in the same model. None of the gender interactions were significant, (see Table 4). Length of marriage was a significant level-2 predictor of some of the level-1 effects, including the actor $(t[173]=-3.27, p<.01)$ and partner $(t[173]=-2.96, p<.01)$ effects for dependent. The strength of the effects attenuated as length of marriage increased, and all effects held when controlling for age.

To explore the unique effects of particular personality disorder characteristics on marital dissatisfaction, we conducted a model including all the significant effects reported above. Only the actor effect for paranoid and partner effect for schizoid remained significant $(p s<.05)$. The actor effect for schizoid $(p=.08)$ and actor effect for antisocial $(p=.10)$ were marginally significant, but all other effects became nonsignificant.

\section{Discussion}

We investigated the relation of personality and marital dissatisfaction in an ethnically diverse sample of couples who all were parents, but varied in the length of their relationships. Two main findings emerged from the analyses. First, using APIM models, normal and abnormal personality traits assessed by multiple measures of personality were related to martial dissatisfaction. These findings are consistent with the intrapersonal component of the VSA model (Karney \& Bradbury, 1995), which predicts that individual differences that couples bring to the marriage, such as personality traits, affect marital satisfaction in interaction with stressful life events and adaptive processes. Second, the effects of personality on marital satisfaction were attenuated in marriages of longer duration.

\subsection{Links between Negative Emotionality and marital dissatisfaction}

We replicated the well-documented link between NE and dissatisfaction (e.g., Donnellan et al., 2007, Robins et al., 2000): husbands and wives who reported high levels of NE, or whose partners reported high levels of NE, described their relationships as more dissatisfying. Notably, the higher-order effects of NE were driven by its stress reaction, alienation, aggression and manipulative components, with the latter two facets evidencing the most robust actor and partner effects. This extends previous research with couples that examined only higher-order NE scales (cf. Robins et al., 2000). Furthermore, these findings suggest that NE facets related to low Agreeableness, aggression and manipulativeness, may be most central for dissatisfaction. This echoes previous research documenting a link between low Agreeableness and dissatisfaction (e.g., Botwin et al., 1997, Donnellan et al., 2004). Also consistent with the relevance of aggression, the IIP scales of vindictiveness and interpersonal coldness evidenced the most robust effects among personality traits specifically related to the interpersonal domain. This suggests that these traits may be particularly deleterious to close relationships (see also Donnellan et al., 2004).

\subsection{Links between Positive Emotionality and marital dissatisfaction}

Consistent with previous research (Robins et al., 2000, Watson et al., 2000), husbands and wives with high levels of PE also reported higher levels of satisfaction in our sample. Further, individuals whose partners' reported high levels of PE also tended to report more satisfying relationships. Replicating previous research (Donnellan et al., 2007), the affiliative components of PE (social closeness and wellbeing) were negatively linked to marital dissatisfaction. However, social potency (a component of agentic $\mathrm{PE}$ ) was significantly and positively associated with dissatisfaction for actors, suggesting that the 
tendency to be socially dominant and persuasive is related to greater dissatisfaction, at least in the context of a long-term romantic relationship. This extends previous research showing that when the agentic components of PE (social potency and achievement) are combined, they are unrelated to relationship quality (Donnellan et al., 2007). It appears that only certain aspects of agentic PE may be related to relationship satisfaction. Furthermore, previous research on social potency and relationship quality has evidenced contradictory findings (e.g., Donnellan et al., 2005, Robins et al., 2002). The opposite associations among the various components of PE and dissatisfaction as well as the inconsistencies with previous research underscore the need for future research to examine the components of PE separately, and in particular, to test hypotheses that might explain their differential associations with marital dissatisfaction.

\subsection{Links between Constraint and marital dissatisfaction}

There was limited evidence for the influence of Constraint on marital dissatisfaction. The higher-order factors did not evidence significant effects, nor did the subscales of the MPQ. This contradicts previous research demonstrating that self-reported Constraint influences romantic outcomes in young adulthood and in dating/cohabitating couples (Donnellan et al., 2007, Robins et al., 2000, Robins et al., 2002; cf. Donnellan et al., 2005). However, it is consistent with other research demonstrating lack of partner effects for Constraint (Donnellan et al., 2007). One explanation for the discrepancies in these findings is that there may be differential associations among Constraint and relationship outcomes in longer-term relationships (such as marriage), especially among older individuals and/or when children are involved. Supporting this, levels of self-control tend to increase as a function of age (Roberts, Caspi, \& Moffitt, 2001), perhaps in concert with role changes such as the transition to marriage and parenting. Research also suggests that remaining with the same partner increases Constraint, at least in young adulthood (Robins et al., 2002). Thus, it may be that older couples or those in relationships of longer duration are higher on Constraint in general, thereby reducing the variance on this trait, and decreasing its likelihood of predicting individual differences in marital dissatisfaction.

Even though normal levels of Constraint were unrelated, two facets of abnormal levels of Constraint, as measured by the SNAP, demonstrated significant associations with dissatisfaction: higher levels of selfand partner-reported impulsivity as well as lower levels of self- and partner-reported propriety were related to higher levels of dissatisfaction. Of note, the effects of impulsivity were driven by husbands' levels of this trait. This aligns with previous research suggesting that men's Constraint influenced their own as well as their female partners' satisfaction, but the same was not true for women (Robins et al., 2000; although we did not replicate this finding for the higher-order factor of Constraint). Robins and colleagues proposed a mechanism whereby men with higher levels of Constraint may be able to achieve greater relationship satisfaction by engaging in more effective problem-solving with their partners rather than impulsively avoiding these discussions, or reacting in a manner that escalates conflict. This notion is consistent with the VSA model's prediction that personality traits indirectly affect marital satisfaction through marital interactions (Karney \& Bradbury, 1995).

\subsection{Links between Openness to Experience and marital dissatisfaction}

Both scales related to Openness to Experience evidenced significant effects: the actor and partner effects for Eccentric Perceptions and the actor effect for Absorption were positively related to dissatisfaction. This is inconsistent with previous research suggesting either little relation of traits 
related to Openness with relationship satisfaction (Donnellan et al., 2004, Donnellan et al., 2005, Robins et al., 2000, Watson et al., 2000), or a negative relationship (Botwin et al., 1997).

\subsection{Links between personality disorder characteristics and marital dissatisfaction}

As predicted, nearly all personality disorder characteristics were positively associated with marital dissatisfaction. Of these, the actor effect for paranoid and the partner effect for schizoid were the most robust, suggesting that elevated Cluster $A$ characteristics may play a greater role in dissatisfaction than Clusters $B$ and $C$ among individuals in committed relationships. These findings add to the literature exploring frank personality disorder diagnoses (e.g., Bouchard et al., 2009) and symptoms (e.g., South et al., 2008) to suggest that elevated traits related to personality disorders are also linked to marital dissatisfaction in a nonclinical sample. In addition, these findings are consistent with the VSA model, as individuals exhibiting aberrant personality styles may behave in ways that produce even more stressful life events and in turn, may have greater difficulty adapting to them, leading to greater marital dissatisfaction. Thus, exploring the mechanisms proposed in the VSA model in the context of abnormal personality traits and problematic interpersonal functioning may be especially fruitful.

\subsection{Effects of personality on marital dissatisfaction were attenuated in marriages of longer duration}

Across personality traits, marital length emerged as a significant moderator, with the actor and partner effects of personality on martial dissatisfaction evidencing weaker effects in longer relationships. Examining the coefficients in these models suggested that in our sample, the effects of personality on marital dissatisfaction were strongest for couples married 12 years or less. Relationship length largely remained a significant moderator when controlling for both partners' ages, ruling out the possibility that the moderation effect was due to developmental changes in personality across the lifespan (e.g., decreases in NE and increases in CON with age; Roberts, Robins, Caspi, \& Trzesniewski, 2003). In addition, it is unlikely that couples' personalities became more similar over time, as cross-partner correlations for personality traits were low and not significant in our sample, and previous research provides little support for greater convergence on personality traits as relationship duration increases (e.g., Watson et al., 2004).

One potential interpretation of these findings is a selection effect, whereby couples whose marriages survive have different personality profiles than those whose marriages end. There is evidence from at least one longitudinal study that husbands who remained in dissatisfied marriages as compared to those who divorced had different personality profiles (Kelly \& Conley, 1987). Similarly, personality factors predict which marriages end in divorce (see Roberts, Kuncel, Shiner, Caspi, \& Goldberg, 2007 for a review). Although we cannot rule out selection effects and the cross-sectional nature of our design limits conclusions about causation, we found no evidence that personality traits varied as a function of marital duration (i.e., correlations of $\mathrm{NE}, \mathrm{PE}$, and $\mathrm{CON}$ with marriage length were generally not significant, ranging from .00 to .25$)$.

Another potential explanation is that the factors that explain variance in marital dissatisfaction change across relationship history. Longitudinal studies on the predictors of marital satisfaction bolster this claim. For example, in a 4-year prospective study, neuroticism predicted initial levels of marital satisfaction, but not rates of change in satisfaction over time; however, observed problem-solving behavior predicted rates of change, but not initial levels of satisfaction (Karney \& Bradbury, 1997). 
Perhaps intrapersonal factors such as personality affect initial levels of satisfaction, but couples' interactions play a greater role in the evolution of satisfaction across the course of the relationship, perhaps as partners' adapt to each others' characteristics. Drawing upon the VSA model, the role of personality traits in relationship satisfaction may weaken as couples develop ways of accommodating or habituating to their partner's personality traits over time that weaken the impact of individual vulnerabilities, such as personality traits. In support of this claim, research using observational methods has demonstrated that for husbands with high levels of neuroticism (but not wives), their partners tend to behave in ways that may enhance the relationship (i.e., providing more positive emotional support), thereby preventing husbands from becoming maritally distressed (Pasch, Bradbury, \& Davila, 1997). However, we are aware of no analogous research literature suggesting accommodation to positive partner characteristics that might account for our findings that the effects of some PE traits on marital dissatisfaction were also attenuated in relationships of longer duration.

\subsection{Strengths and limitations}

The findings of the present study should be interpreted in the context of several limitations. First, the cross-sectional nature of the design limits conclusions about causation and cannot rule out the possibility of selection effects. Second, we relied on self-reported measures of personality and satisfaction, rather than observed marital interactions/quality. Because we did not investigate marital interactions we could not test mediators of the influence of personality and satisfaction, and thus, we cannot offer evidence regarding mechanisms underlying these effects or directly test the mechanisms of the VSA model. Third, because there is not an established method for estimating the size of effects within APIM, the magnitude of effects were difficult to quantify. However, we tested multiple traits within the same model in order to investigate whether the effects of particular traits held after accounting for other traits with significant zero-order associations with marital satisfaction.

The study also has several strengths. First, extending much of the research on personality and satisfaction (cf. Donnellan et al., 2007, Robins et al., 2000), we employed APIM to test our hypotheses. This allowed us to investigate both actor and partner effects, gender differences, and moderators of these effects. Second, we investigated both normal and abnormal personality traits, using multiple measures of personality, with attention to both higher-order factors and their subtraits. This provided a richer understanding of the influence of personality on satisfaction. Third, several characteristics of our sample were of note. All couples were raising a young child, but varied in age, marital duration and ethnic/racial background, increasing the generalizability of the results to the larger population of married parents.

\section{Acknowledgment}

This research was supported by the Kovler Research Fund of The Family Institute.

\section{References}

American Psychiatric Association, 2000 American Psychiatric Association (2000). Diagnostic and statistical manual of mental disorders (4th ed., revised ed.). Washington, DC

Asendorpf and Wilpers, $1998 \mathrm{~J}$. Asendorpf, S. Wilpers Personality effects on social relationships Journal of Personality and Social Psychology, 74 (6) (1998), pp. 1531-1544 
Bono et al., 2002 J. Bono, T. Boles, T. Judge, K. Lauver The role of personality in task and relationship conflict Journal of Personality, 70 (3) (2002), pp. 311-344

Botwin et al., 1997 M. Botwin, D. Buss, T. Shackelford Personality and mate preferences: Five factors in mate selection and marital satisfaction Journal of Personality, 65 (1) (1997), pp. 107-136

Bouchard et al., 2009 S. Bouchard, S. Sabourin, Y. Lussier, E. Villeneuve Relationship quality and stability in couples when one partner suffers from borderline personality disorder Journal of Marital and Family Therapy, 35 (4) (2009), pp. 446-455

Carver, 1997 C. Carver Adult attachment and personality: Converging evidence and a new measure Personality and Social Psychology Bulletin, 23 (8) (1997), pp. 865-883

Caspi et al., 2005 A. Caspi, B. Roberts, R. Shiner Personality development: Stability and change Annual Review of Psychology, 56 (1) (2005), pp. 453-484

Caughlin et al., $2000 \mathrm{~J}$. Caughlin, T. Huston, R. Houts How does personality matter in marriage? An examination of trait anxiety, interpersonal negativity, and marital satisfaction Journal of Personality \& Social Psychology, 78 (2) (2000), pp. 326-336

Church, 1994 A.T. Church Relating the Tellegen and Five-Factor models of personality structure Journal of Personality and Social Psychology, 67 (1994), pp. 898-909

Clark and Watson, 1999 L.A. Clark, D. Watson Temperament: A new paradigm for trait psychology L.A. Pervin, O.P. John (Eds.), Handbook of personality: Theory and research (2nd ed.), Guilford, New York (1999)

Conger et al., 1999 R. Conger, M. Rueter, G. Elder Jr. Couple resilience to economic pressure Journal of Personality \& Social Psychology, 76 (1) (1999), pp. 54-71

Donnellan et al., 2007 M. Donnellan, K. Assad, R. Robins, R. Conger Do negative interactions mediate the effects of negative emotionality, communal positive emotionality, and constraint on relationship satisfaction? Journal of Social \& Personal Relationships, 24 (4) (2007), pp. 557-573

Donnellan et al., 2004 M. Donnellan, R. Conger, C. Bryant Big five and enduring marriages Journal of Research in Personality, 38 (5) (2004), pp. 481-504

Donnellan et al., 2005 M. Donnellan, D. Larsen-Rife, R. Conger Personality, family history, and competence in early adult romantic relationships Journal of Personality \& Social Psychology, 88 (3) (2005), pp. 562-576

Goldberg, 1993 L.R. Goldberg The structure of phenotypic personality traits American Psychologist, 48 (1993), pp. 26-34

Graziano et al., 1996 W. Graziano, L. Jensen-Campbell, E. Hair Perceiving interpersonal conflict and reacting to it: The case for agreeableness Journal of Personality and Social Psychology, 70 (4) (1996), pp. 820-835

Harlan and Clark, 1999 E. Harlan, L.A. Clark Short forms of the schedule for nonadaptive and adaptive personality (SNAP) for self and collateral ratings: Development, reliability and validity Assessment, 6 (1999), pp. 131-145

Horowitz et al., 1988 L.M. Horowitz, S.E. Rosenberg, B.A. Baer, G. Ureno, V.S. Villasenor Inventory of interpersonal problems: Psychometric properties and clinical applications Journal of Consulting and Clinical Psychology, 56 (1988), pp. 885-892

Karney and Bradbury, 1995 B. Karney, T. Bradbury The longitudinal course of marital quality and stability: A review of theory, methods, and research Psychological Bulletin, 118 (1) (1995), pp. 3-34 
Karney and Bradbury, 1997 B. Karney, T. Bradbury Neuroticism, marital interaction, and the trajectory of marital satisfaction Journal of Personality \& Social Psychology, 72 (5) (1997), pp. 1075-1092

Kashy and Kenny, 2000 D.A. Kashy, D.A. Kenny The analysis of data from dyads and groups H.T. Reis, C.M. Judd (Eds.), Handbook of research methods in social psychology, Cambridge University Press, New York (2000), pp. 451-477

Kelly and Conley, 1987 E. Kelly, J. Conley Personality and compatibility: A prospective analysis of marital stability and marital satisfaction Journal of Personality and Social Psychology, 52 (1) (1987), pp. 27-40

Kinnunen and Pulkkinen, 2003 U. Kinnunen, L. Pulkkinen Childhood socio-emotional characteristics as antecedents of marital stability and quality European Psychologist, 8 (4) (2003), pp. 223-237

Kochanska et al., 2004 G. Kochanska, A. Friesenborg, L. Lange, M. Martel Parents' personality and infants' temperament as contributors to their emerging relationship Journal of Personality and Social Psychology, 86 (5) (2004), pp. 744-759

Lawrence et al., 2008 E. Lawrence, A. Rothman, R. Cobb, M. Rothman, T. Bradbury Marital satisfaction across the transition to parenthood Journal of Family Psychology, 22 (1) (2008), pp. 41-50

Loranger et al., 1994 A.W. Loranger, et al. International personality disorder examination (IPDE) the world health organization/alcohol, drug abuse, and mental health administration international pilot study of personality disorders Archives of General Psychiatry, 51 (1994), pp. 215-224

Markon et al., 2005 K. Markon, R. Krueger, D. Watson Delineating the structure of normal and abnormal personality: An integrative hierarchical approach Journal of Personality and Social Psychology, 88 (1) (2005), pp. 139-157

McCrae and Costa, 1990 R.R. McCrae, P.T. Costa Personality in adulthood Guilford Press, New York (1990)

Pasch et al., 1997 L. Pasch, T. Bradbury, J. Davila Gender, negative affectivity, and observed social support behavior in marital interaction Personal Relationships, 4 (4) (1997), pp. 361-378

Patrick et al., 2002 C. Patrick, J. Curtin, A. Tellegen Development and validation of a brief form of the Multidimensional Personality Questionnaire Psychological Assessment, 14 (2002), pp. 150-163

Roberts et al., 2001 B. Roberts, A. Caspi, T. Moffitt The kids are alright: Growth and stability in personality development from adolescence to adulthood Journal of Personality and Social Psychology, 81 (4) (2001), pp. 670-683

Roberts et al., 2007 B. Roberts, N. Kuncel, R. Shiner, A. Caspi, L. Goldberg The power of personality: The comparative validity of personality traits, socioeconomic status, and cognitive ability for predicting important life outcomes Perspectives on Psychological Science, 2 (4) (2007), pp. 313345

Roberts et al., 2003 B.W. Roberts, R.W. Robins, A. Caspi, K. Trzesniewski Personality trait development in adulthood J. Mortimer, M. Shanahan (Eds.), Handbook of the life course, Kluwer Academic, New York, NY (2003), pp. 579-598

Robins et al., 2000 R. Robins, A. Caspi, T. Moffitt Two personalities, one relationship: Both partners' personality traits shape the quality of their relationship Journal of Personality and Social Psychology, 79 (2) (2000), pp. 251-259

Robins et al., 2002 R. Robins, A. Caspi, T. Moffitt It's not just who you're with, it's who you are: Personality and relationship experiences across multiple relationships Journal of Personality, 70 (6) (2002), pp. 925-964 
Rothbart et al., 2000 M.K. Rothbart, S.A. Adahi, D.E. Evans Temperament and personality: Origins and outcomes Journal of Personality and Social Psychology, 78 (2000), pp. 122-135

Schmitt et al., 2007 M. Schmitt, M. Kliegel, A. Shapiro Marital interaction in middle and old age: A predictor of marital satisfaction? International Journal of Aging \& Human Development, 65 (4) (2007), pp. 283-300

Snyder and Aikman, 1999 D.K. Snyder, G.G. Aikman The marital satisfaction inventory-Revised M.E. Maruish (Ed.), The use of psychological testing for treatment planning and outcome assessment (2nd ed.), Erlbaum, Mahwah, NJ (1999), pp. 1173-1210

South et al., 2008 S. South, R. Krueger, W. Johnson, W. lacono Adolescent personality moderates genetic and environmental influences on relationships with parents Journal of Personality and Social Psychology, 94 (5) (2008), pp. 899-912

South et al., 2008 S. South, E. Turkheimer, T. Oltmanns Personality disorder symptoms and marital functioning Journal of Consulting and Clinical Psychology, 76 (5) (2008), pp. 769-780

Tellegen, $1985 \mathrm{~A}$. Tellegen Structure of mood and personality and their relevance to assessing anxiety, with an emphasis on self-report A.H. Tuma, J.D. Maser (Eds.), Anxiety and the anxiety disorders, Elrbaum, Hillsdale, NJ (1985), pp. 681-706

Watson and Clark, 1992 D. Watson, L.A. Clark On traits and temperament: General and specific factors of emotional experience and their relations to the five-factor model Journal of Personality, 60 (1992), pp. 443-476

Watson et al., 2008 D. Watson, L. Clark, M. Chmielewski Structures of personality and their relevance to psychopathology: II. Further articulation of a comprehensive unified trait structure Journal of Personality, 76 (6) (2008), pp. 1545-1586

Watson et al., 2000 D. Watson, B. Hubbard, D. Wiese General traits of personality and affectivity as predictors of satisfaction in intimate relationships: Evidence from self- and partner-ratings Journal of Personality, 68 (3) (2000), pp. 413-449

Watson et al., 2004 D. Watson, E. Klohnen, A. Casillas, E. Nus Simms, J. Haig, D. Berry Match makers and deal breakers: Analyses of assortative mating in newlywed couples Journal of Personality, 72 (5) (2004), pp. 1029-1068

Zimmerman, 1994 M. Zimmerman Diagnosing personality disorders: A review of issues and research models Archives of General Psychiatry, 51 (3) (1994), pp. 225-245 